\title{
MIGRAÇÃO: UM MAPEAMENTO DA CIDADE DE ORIGEM DOS DOCENTES DO CENTRO ACADÊMICO DE VITÓRIA DA UFPE E UMA BREVE PERCEPÇÃO DOS MESMOS SOBRE ESSA MUDANÇA
}

\author{
MIGRATION: A MAPPING OF THE HOMETOWN OF TEACHERS \\ FROM ACADEMIC CENTER OF VICTORY AT UFPE AND A \\ BRIEF PERCEPTION OF THEM ON THIS CHANGE \\ Kátia Elaine de Vasconcelos e Silva ${ }^{1}$ \\ Jeckson de Andrade Silva ${ }^{2}$ \\ Maria Elisangela Fagundes da Silva Viana ${ }^{3}$
}

1

Mestra em Gestão Pública para o Desenvolvimento do Nordeste / UfPE, Secretária Geral das Coordenações dos Cursos de Graduação do Centro Acadêmico de Vitória (CAV) da UPPE - Vitória de Santo Antão, PE - e-mail: katiaevs@hotmail.com

2

Mestre em Gestão Pública - MGP/UfPE, Bacharel em Turismo-Ufpe, Especialista em Linguística Aplicada à Língua Inglesa FAFIRE, Coordenador Administrativo do

Centro de Biociências -

e-mail: jecksonandrade@

hotmail.com

3

Mestra em Gestão Pública para o Desenvolvimento do Nordeste - UFPE, Secretária da Coordenação da Área II do Centro de Ciência Exatas e da Natureza - UFPE - e-mail: mariaelisangelazooo@ yahoo.com.br
RESUMo: Este texto fará uma síntese dos conceitos ligados à migração, processos de mapeamento e interiorização das universidades, buscando contextualizar o referido trabalho através de autores especializados nas áreas citadas. Ele apresentará os resultados sobre o levantamento feito entre os docentes do Centro Acadêmico de Vitória da Universidade Federal de Pernambuco, e analisará posteriormente a influência desses professores no processo de interiorização e na implantação do referido Campus, inaugurado em junho de 2016 na cidade de Vitória de Santo Antão. Também identificará a percepção dos mesmos sobre a sua escolha de ter saído de suas cidades para trabalhar em um Campus do interior de Pernambuco, através dos dados obtidos na coleta durante a pesquisa.

Palavras-chave: Migração e Mapeamento Cartográfico. Universidade. Interiorização.

ABSTRACT: This research project will give a brief overview of the concepts related to migration, processes of mapping and internalization of universities, seeking to contextualize the mentioned work through specialized authors in the mentioned areas. It will present the results about the survey done among the professors of the Vitória's Academic Center of the Federal University of Pernambuco. Further, it will analyze the influence of those professors in incorporate the process and its implementation within the Campus, which was inaugurated in June 2016 in Vitória de Santo Antão City. Additionally, the project will present the professionals' perception of how they feel about having left their cities to work in a Campus in the interior of Pernambuco, through the data collected during the research.

KEYWORDS: Migration and Cartographic Mapping. University. Interiorization.

\section{INTRODUÇÃO}

O Governo Federal, desde 2004, tem se preocupado em interiorizar e expandir as universidades públicas federais em todo o Brasil. Diante disso, a partir de 2006, a UfPE iniciou o seu processo de inte- 
riorização, através da criação do Centro Acadêmico de Caruaru - cAA, na cidade de Caruaru (Agreste Pernambucano) e Centro Acadêmico de Vitória - CAV, na cidade de Vitória de Santo Antão (Zona da Mata Pernambucana).

A implantação de uma universidade em uma cidade do interior, muitas vezes carente de faculdades, provoca grande interesse por parte dos jovens e de suas famílias, como também dos docentes da cidade e de outras regiões que percebem que um Campus recém-instalado poderá gerar muito mais oportunidades do que um já implantado há muitos anos, pois o primeiro ainda está se estruturando, carente de profissionais, pesquisas, projetos e trabalhos acadêmicos em geral e por isso geralmente dão preferência a esse novo Campus para trabalhar e estudar.

Segundo Araújo (2013), a expansão da universidade pública é hoje uma das principais políticas setoriais num processo contraditório de "desenvolvimento urbano-regional", ainda que seja difícil identificar tal política como algo relacionado a grandes projetos de integração e desenvolvimento regional de uma maneira mais efetiva.

Há também a questão da mobilidade urbana, pois em uma cidade interiorana esse problema é bastante reduzido, trazendo com ela muitas vezes uma melhor qualidade de vida, entre outros benefícios, acrescentando assim mais motivação aos que procuram ingressar em um Campus universitário do interior.

Neste trabalho serão apresentados no referencial teórico os conceitos da política de interiorização das Instituições de Estudos Superior (IES) das universidades, processo migração no Brasil e mapeamento cartográfico, como também será retratada a história do Centro Acadêmico de Vitória (CAv) e sua implantação em 2006 na cidade de Vitória de Santo Antão.

Será utilizada uma pesquisa aplicada e de natureza quali-quantitativa, alicerçada nos dados obtidos através de questionário respondido pelos professores do cAv e também exploratória, pois se desenvolverá a partir de fontes primárias e secundárias. Será feito um levantamento bibliográfico de autores especializados que discutem os temas em questão. A pesquisa documental se dará através de consulta ao banco de dados do setor de Gestão de Pessoas do cav.

Para a construção dos mapas será utilizado o programa do site BatchGeo e para a criação dos gráficos estatísticos será utilizado o Google Docs gerados a partir dos dados coletados no questionário aplicado aos docentes, através de aplicação de questionários destinados aos docentes do CAV, objeto de estudo desse trabalho.

Portanto, a partir dos resultados da pesquisa, este trabalho objetiva identificar a origem dos professores vinculados ao Centro, como também analisar brevemente quais os benefícios que os mesmos trouxeram para a cidade, através de desenvolvimento de projetos, eventos, etc, direcionados às comunidades locais e a percepção dos mesmos em 
ter saído dos seus estados em busca de novos desafios e novas oportunidades nas suas vidas profissionais e acadêmicas e se tem interesse em permanecer nela nos próximos anos.

\section{INTERIORIZAÇÃO}

Um dos principais objetivos da educação, inclusive do Ensino Superior, é proporcionar a formação do cidadão, disseminando o conhecimento e criando formas de redução das desigualdades sociais.

Etzkowitz (2009) afirma que, a principal missão da universidade é assumir o desenvolvimento socioeconômico, a criação de empregos, a inovação e a sustentabilidade.

As Universidades, enquanto difusoras do conhecimento e da formação crítica dos indivíduos, assumem a importante função de fomentar pesquisas que se revertam na construção de conhecimentos, contribuindo para uma sociedade sustentável mediante os pilares do ensino, pesquisa, extensão e gestão (UFPE, 2010).

Chauí (2003) afirma que as universidades são instituições sociais inseparáveis da ideia de democracia e da democratização do saber. Por conseguinte, o Governo Federal através do Ministério da Educação MEC, deu início a uma política de Interiorização do Ensino Superior e Técnico almejando a expansão da Educação (UFPE, 2010).

A Educação Superior tem experimentado a expansão em todo o mundo, inclusive em países periféricos, com vistas a garantir maior acesso, principalmente por parte das camadas sociais menos favorecidas (TEIXEIRA et $A L$, 2012; MCCOWAN, 2007).

Especialmente no Brasil, houve um conjunto de iniciativas do Governo Federal que buscaram a ampliação e interiorização do Ensino Superior e que ainda estão sendo implementadas no país. Entre estas iniciativas governamentais, destacam-se o Programa Expandir criado em 2005, o Programa de Apoio a Planos de Reestruturação e Expansão das Universidades Federais (REUNI) instituído por meio do Decreto № 6.096 de 24 de abril de 2007, e a criação do Programa Universidade para Todos (PROUNI).

A interiorização do Ensino Superior no Brasil tem permitido levar às cidades do interior, em destaque às mais afastadas das capitais, a chance de novos profissionais se inserirem na cidade trazendo novas opções de desenvolvimento das mesmas nas diversas formas. Essa realidade aparece a partir das instalações das Universidades e Institutos Federais que oferecem um ensino público de qualidade e gratuito. A UFPE hoje está entre as instituições que vêm cumprindo esse desafio da interiorização, como por exemplo, a instalação do Centro Acadêmico de Vitória - CAv, objeto desse estudo, e Centro Acadêmico do Agreste CAA, oferecendo cursos de graduação e pós-graduação (especialização, mestrado e doutorado).

O reflexo dessa interiorização gera na sociedade local a demanda por novos cursos de graduação que irão atender à demanda local 
e, consequentemente, a ampliação de novas vagas nas instituições federais e isso vai requerer mais profissionais (técnicos administrativos e docentes) que irão colaborar com o desenvolvimento econômico, social e acadêmico dentro da cidade e nas circunvizinhanças onde o Campus está instalado.

\section{O PROCESSO DE MIGRAÇÃO NO BRASIL}

Migração consiste no ato da população deslocar-se espacialmente, ou seja, pode se referir à troca de país, estado, região, município ou até de domicílio. As migrações podem ser desencadeadas por fatores religiosos, psicológicos, sociais, econômicos, políticos e ambientais (FRANCISCO, 2014).

O processo de migração acontece geralmente por desastres naturais ou motivos econômicos. A população de um país não é modificada apenas pelas mortes e nascimentos de seus habitantes, é preciso considerar também os movimentos de entrada e de saída, ou seja, as migrações que ocorrem em seu território. As migrações internas são aquelas que se processam no interior de um país como, por exemplo, êxodo rural, ou seja, a migração do campo para a cidade, o que é frequente no Brasil e que se intensificaram nas últimas cinco décadas.

A migração interna corresponde ao deslocamento de pessoas dentro de um mesmo território, dessa forma pode ser entre regiões, estados e municípios. Tal deslocamento não provoca modificações no número total de habitantes de um país, porém, altera as regiões envolvidas nesse processo. No Brasil, um dos fatores que exercem maior influência nos fluxos migratórios é o de ordem econômica, uma vez que o modelo de produção capitalista cria espaços privilegiados para instalação de indústrias, forçando indivíduos a se deslocarem de um lugar para outro em busca de melhores condições de vida e à procura de emprego para suprir suas necessidades básicas de sobrevivência. (FRANCISCO, 2014).

Um modelo de migração muito comum no Brasil, que se intensificou nas últimas décadas é o êxodo rural, ou seja, a migração do campo para a cidade. Porém, a partir da década de 90 tem acontecido o Êxodo urbano, que é deslocamento inverso ao êxodo rural, ou seja, da cidade para o campo, pois muitas pessoas tem procurado viver no interior buscando qualidade de vida e oportunidades de trabalho que não estavam mais encontrando nas capitais.

Desde os finais da década de 1990 que o custo e a qualidade de vida nas grandes cidades têm exercido uma forte influência de "deslocalização" da população dessas cidades para zonas do interior e/ou rurais. A par destas contrariedades, a extensão da banda larga por todo o território tem permitido a profissionais independentes e a "teletrabalhadores" esta "deslocalização" para as regiões de 'baixa densidade'. A questão econômica tem sido um dos fortes impulsionadores do êxodo urbano no Primeiro Mundo. (santana, 2013.) 
A região Sudeste do Brasil, até o final do século xx, recebeu a maior quantidade de fluxos migratórios do país, principalmente o estado de São Paulo, pelo fato de fornecer maiores oportunidades de emprego em razão do processo de industrialização desenvolvido. (FRANCISCO, 2014).

Isso está demonstrado nos mapas abaixo na FIGURA 1, em que aparece esse processo migratório ao longo dos anos:

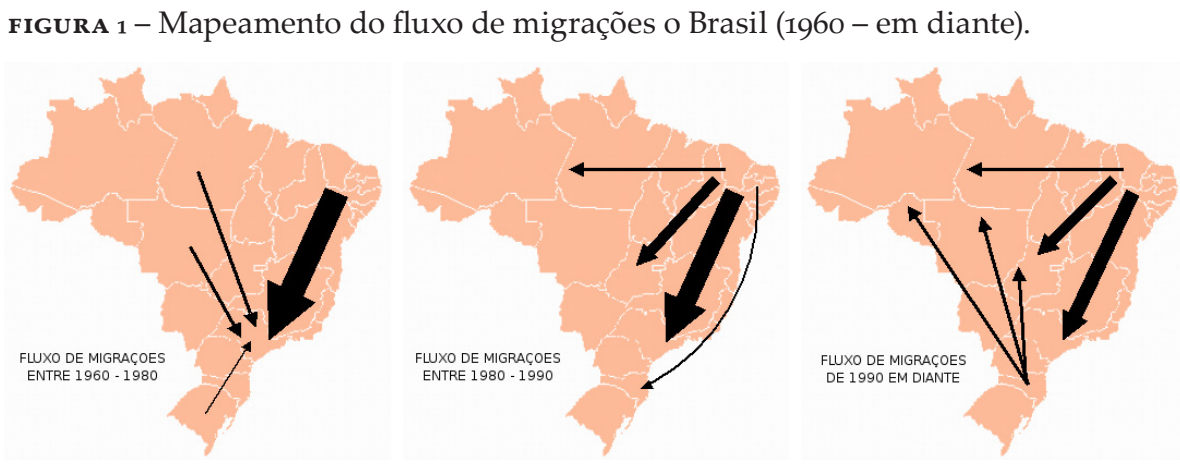

FONTE: Wikipédia, 2017.

Ainda hoje, conforme dados estatísticos do IBGE, o Sudeste continua captando boa parte dos migrantes brasileiros. A região recebe muito mais gente do que perde. O Centro-Oeste também recebe mais migrantes do que perde, sendo, atualmente, o principal destino dos fluxos migratórios no Brasil. O Sul e o Norte são regiões onde o volume de entrada e saída de migrantes é mais equilibrado. (IBGE, 2014).

A Região Nordeste tem recebido cada vez mais migrantes, sendo a maioria proveniente do Sudeste (retorno), porém, continua sendo a região que mais perde população para as demais. Outro aspecto das migrações internas no Brasil é que os fluxos são mais comuns dentro dos próprios estados ou regiões de origem do migrante. Esse fato se deve à descentralização da atividade industrial no país, antes concentrada na Região Sudeste e em Regiões Metropolitanas. (FRANCISCO, 2014).

As migrações internas têm sido alvo de vários estudos e de análise mais aprofundada, não apenas como resultantes de eventuais desequilíbrios econômicos, sociais ou demográficos, mas, principalmente, como elementos da organização espacial de uma sociedade.

\section{MAPEAMENTO CARTOGRÁFICO}

Quando se pretende planejar qualquer atividade que de alguma maneira se relaciona com o espaço físico é necessário o reconhecimento desse espaço. Assim, passa a ser indispensável alguma forma de se visualizar a região da superfície física desejada, na qual irá se desenvolver determinada atividade e, para alcançar esse objetivo, o processo de mapeamento cartográfico é utilizado.

Entende-se por mapeamento a aplicação do processo cartográfico sobre uma coleção de dados ou informações, com vistas à obtenção de uma representação gráfica da realidade perceptível, comunicada a 
partir da associação de símbolos e outros recursos gráficos que caracterizam a linguagem cartográfica. (IBGE, 2014).

Na representação do pensamento geográfico, os mapas estão entre os mais antigos. Vários registros mostram que eles existiam desde a Grécia Antiga e até mesmo no Império Romano, entre tantas outras civilizações da Antiguidade.

Os primeiros eram feitos de madeira, esculpidos ou pintados, ou desenhados sobre a pele de animais. Suas funções incluíam conhecer as áreas dominadas e as possibilidades de ampliação das fronteiras, demarcar territórios de caça e representar a visão de mundo que esses povos tinham. Sobre isso Martinelli (2003), professor de Cartografia Estratégica do Departamento de Geografia da Universidade de São Paulo (USP) afirma: "desde sempre, o homem registra o espaço onde vive. Trata-se de uma necessidade social".

Os mapas se transformaram em um recurso muito importante para a expansão das civilizações, eles tornaram-se mais do que uma simples ferramenta de orientação e localização, e o seu desenvolvimento foi colocado como forma de poder. Eles foram primordiais para a definição das estratégias militares de guerra e na conquista e dominação de outros povos. Por trás de um mapa cartográfico há muito interesse de ordem política, de cunho pessoal e econômico, pois ele sempre esteve ligado a objetivos específicos e determinados de uma região ou poder público.

$\mathrm{Na}$ época das grandes navegações e dos descobrimentos marítimos (entre os séculos 15 e 16), por exemplo, os cartógrafos estavam presentes em cada expedição realizada. Sua função não era exatamente ajudar na localização, mas registrar e tornar pública a descoberta de novos territórios. (MOçO, 2011).

Com outras palavras, Barcelar (2015) esclarece que, com o passar dos anos, novas tecnologias, como a bússola, o astrolábio, o telescópio e outras, permitiram avanços incríveis. Galileu desenvolveu um método com base nos eclipses das luas do planeta Júpiter, resolvendo assim o problema das longitudes nos mapas. A partir da segunda metade do século XVIII, o mundo foi finalmente conhecido com as suas devidas coordenadas geográficas.

Na próxima página, seguem dois exemplos de mapas representados na FIGURA 02 e FIGURA 03, do século 16 e século 21, para melhor visualização da evolução dos mapas no mundo.

A grande virada na utilização da cartografia se dá exatamente com a revolução da microinformática, a partir dos anos 1980, acompanhada de sua prima-irmã, a Internet, e a disponibilidade gratuita de imagens de satélite, dados e mapas georreferenciados. $\mathrm{O}$ avanço de tais tecnologias tornou possível a ampliação do acesso à cartografia, permitindo finalmente a incursão de novos grupos sociais à ferramenta de estratégica importância para a disputa por territórios. (FREIRE; FERNANDES, 2010). 


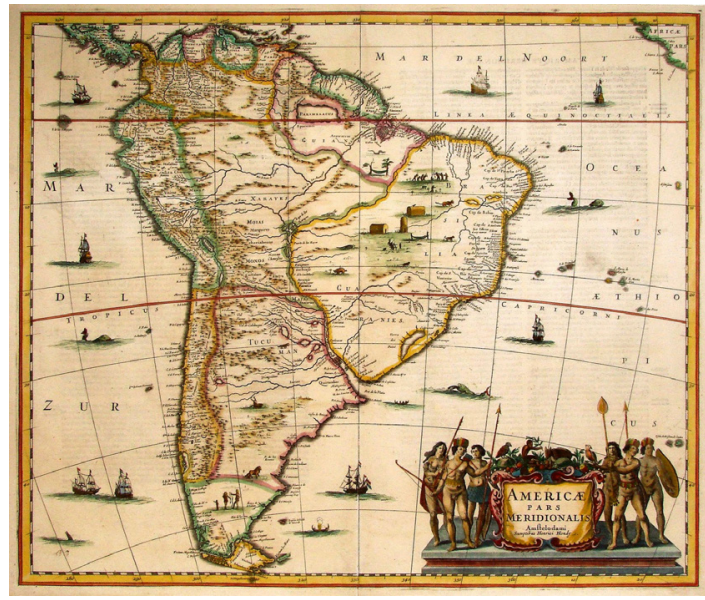

FIGURA 02 - Mapa

Brasil (Século 16)

FONTE: Acervo do

Conhecimento - ACH (2017)

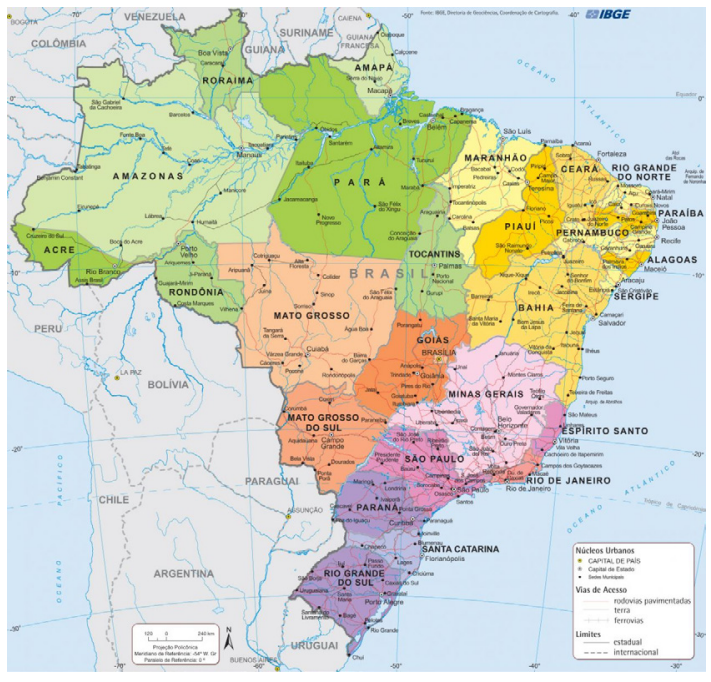

FIGURA 03 - Mapa do

Brasil (Século 20)

FONTE: Site “Já andei por aí" (2017).

Hoje, podemos ver como são normalmente encontrados os mapas digitais que possuem acesso aos bancos de dados mais completos que existe, formando os Sistemas de Informações Geográficas (GIS). E assim, os mapas poderão ser formados de acordo com a necessidade de quem os procura, independente da formação acadêmica ou da classe social do pesquisador.

\section{O CENTRO ACADÊMICO DE VITÓRIA - CAV}

O contrato de adesão ao Programa de Apoio ao Plano de Reestruturação e Expansão das Universidades Federais (Reuni), assinado pela Universidade Federal de Pernambuco (UFPE), previa a ampliação do número de cursos e aumento de vagas para os estudantes. $\mathrm{O}$ número de cursos cresceria de 84 para 106, até 2012. E a oferta de cursos noturnos, de 22 para 35. As vagas passarão de 5.285 para 6.707, no mesmo período. Com o Reuni, foram investidos mais de R 66 milhões na reestruturação. (MEC, 2008)

A oferta de educação superior pública está em pleno processo de expansão. A interiorização das universidades federais é uma das metas do programa de expansão universitária. Na primeira fase, 61 novos 
campi e 10 universidades foram criadas. A segunda fase, o Programa de Apoio ao Plano de Reestruturação e Expansão das Universidades Federais (Reuni), prevê o aumento de vagas e melhor aproveitamento dos recursos físicos e humanos das federais. Todas as 53 universidades federais já apresentaram os planos de reestruturação e as ações começam a ser implantadas. (MEC, 2008).

Antes de 2003, havia 148 campi em 114 municípios, entre 2003 e 2010, esse número passou para 274 campi em 230 municípios. Ao final de 2014, 63 federais deverão estar em 321 campi, atendendo 275 municípios. Em 11 anos, a interiorização do ensino público federal permitiu ao Brasil mais que dobrar o acesso de estudantes à educação superior. Cresceu também o percentual de professores com doutorado que passou de 50,9\% em 2003 para 68,8\% em 2012, colaborando para o Brasil ocupar o $13^{\mathrm{O}}$ lugar entre os países com maior produção científica. (UFPE, ASCOM, 2013a)

O Centro Acadêmico de Vitória foi o segundo instalado durante esse processo de interiorização da UFPE em julho de 2006, o primeiro foi o Centro Acadêmico do Agreste - CAA, em janeiro do mesmo ano, que fica localizado na cidade de Caruaru-PE. (UFPE, CAV, 2009).

O cav da ufPe nasceu da determinação do Governo Federal de interiorizar a educação superior pública em consonância com o fato da Universidade Federal de Pernambuco ser a principal instituição federal de ensino superior da região Nordeste, estando entre as dez melhores do País, concorreu para a criação e consolidação do Campus de Vitória. (UFPE, CAV, 2009).

Ele está localizado na cidade de Vitória de Santo Antão, Zona da Mata Sul de Pernambuco e hoje oferece 6 (seis) cursos, sendo eles: Licenciatura em Ciências Biológicas, Bacharelado em Nutrição, Bacharelado em Enfermagem, Bacharelado em Saúde Coletiva, Licenciatura em Licenciatura em Educação Física e Bacharelado em Educação Física, totalizando 1.710 alunos matriculados em 2017.1, segundo levantamento realizado no Sistema de Gerenciamento Acadêmico da UfPE (Sig@ UFPE), conforme distribuição abaixo na TABELA 01:

Tabela 01 - Total de Alunos Matriculados nos Cursos de Graduação do CAV em 2017.1

\begin{tabular}{|l|c|}
\hline \multicolumn{1}{|c|}{ CURSO } & $\begin{array}{c}\text { ALUNOS MATRICULADOS } \\
\text { EM 2017.1 }\end{array}$ \\
\hline Licenciatura em Ciências Biológicas & 403 \\
\hline Bacharelado em Nutrição & 244 \\
\hline Bacharelado em Enfermagem & 267 \\
\hline Bacharelado em Saúde Coletiva & 191 \\
\hline Licenciatura em Educação Física & 336 \\
\hline Bacharelado em Educação Física & $\mathbf{2 6 9}$ \\
\hline TOTAL & $\mathbf{1 . 7 1 0}$ \\
\hline
\end{tabular}

Fonte: Sig@. Elaborado pela autora, 2017. 
Além dos cursos graduação, o Campus possui dois Programas de Mestrado Acadêmico (Strictu Sensu) e um Programa de Residência (Lato Sensu), sendo eles Programa de Pós-Graduação em Saúde Humana e Meio Ambiente, Programa de Pós-Graduação em Nutrição, Atividade Física e Plasticidade Fenotípica e o Programa de Residência Multiprofissional de Interiorização de Atenção à Saúde.

Conforme relatório institucional do CAV, o Centro foi criado com o objetivo de proporcionar à região melhoria do nível educacional, condição imprescindível ao desenvolvimento humano e social, de forma a proporcionar um marco positivo na Interiorização do ensino superior (UFPE, CAV, 2009).

Com relação aos recursos humanos do Campus Vitória, o mesmo possui em abril de 2017 um corpo docente formado por 148 professores efetivos (103 mulheres e 45 homens), e um total de 73 professores substitutos ( 25 homens e 48 mulheres), isso distribuído entre mestres, doutores e pós-doutores, sendo os mesmos responsáveis pelas atividades de ensino, pesquisa, extensão e também de gestão do cAV, pois alguns possuem cargo de Diretor, Vice-Diretor, Coordenadores e ViceCoordenadores de Curso de Graduação e Pós-Graduação, entre outras atividades de gestão, conforme GRÁFICO 01 abaixo:

GRÁfICO 01 - Quadro de Docentes do caV

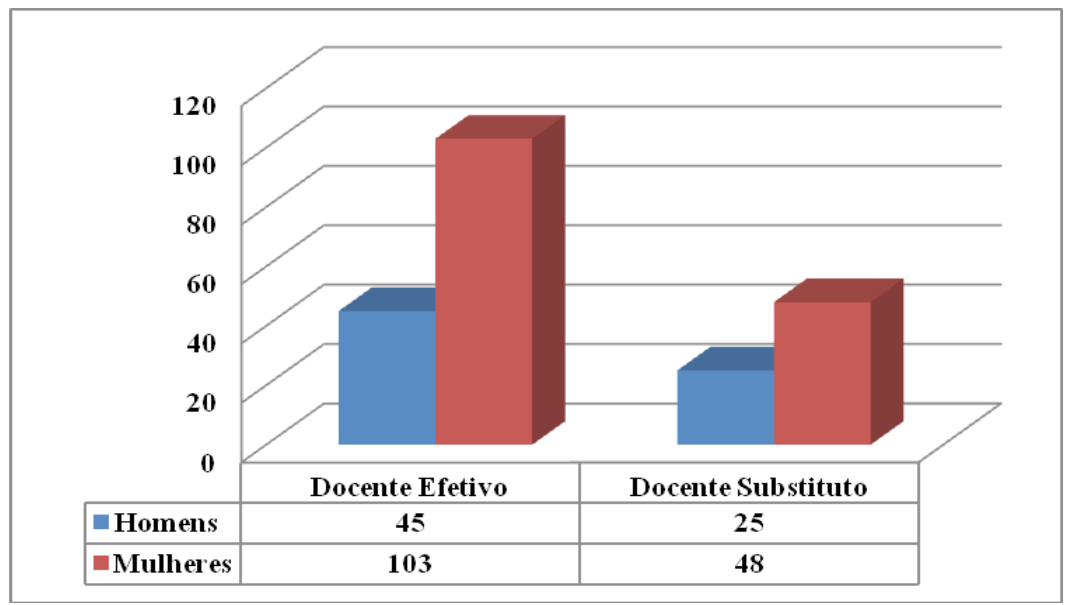

FONTE: Gestão de Pessoas do cav. Elaborado pela autora, 2017.

Quanto aos técnicos administrativos em educação, o Centro possui um total de 86 servidores, sendo 52 homens e 34 mulheres, distribuídos entre os cargos de nível fundamental, médio e superior, no qual muitos já possuem titulação bem superior à exigida para o provimento dos seus respectivos cargos, como cursos de graduação, especialização, mestrado e doutorado, conforme TABELA 02 abaixo:

Tabela 02 - Total de técnicos administrativos em educação do cAV

\begin{tabular}{|c|c|}
\hline Homens & 52 \\
\hline Mulheres & 34 \\
\hline TOTAL & 86 \\
\hline
\end{tabular}

Fonte: Gestão de Pessoas do cav. Elaborado pela autora, 2017. 
O cav conta também com serviços terceirizados, como auxiliares de serviços gerais e vigilantes, totalizando 39 funcionários (24 vigilantes, distribuídos em escala de trabalho e 15 na função de serviços gerais). E vem ampliando a cada ano o quadro de servidores (técnicos administrativos e docentes), através de realização de concursos públicos, visando agilizar rotinas administrativas e atividades acadêmicas (ensino, pesquisa e extensão) diante de novas e crescentes demandas que aparecem no dia-a-dia do Centro.

O Centro Acadêmico de Vitória continua crescendo e ampliando suas atividades na intenção de garantir o progresso contínuo do desempenho de suas ações, tendo em vista seu papel de promoção da interiorização do ensino de qualidade voltado para a formação acadêmica e científica. (UFPE, CAV, 2009).

\section{DADOS E DISCUSSÃO}

A partir do questionário aplicado aos docentes do CAV no período de 05 a 12 de abril de 2017, que totalizam 221 (sendo 148 efetivos e 73 substitutos), 44 responderam às perguntas ( $95,5 \%$ efetivos e $4,5 \%$ substitutos), ou seja, obteve-se um percentual de $20 \%$ de respostas, sendo que $59,1 \%$ são mulheres e $40,9 \%$ são homens.

A partir dessas respostas, foi feito um levantamento e análise das mesmas, respondendo assim as questões sobre origem das cidades dos docentes e as suas percepções sobre essa mudança e a influência disso nas suas vidas profissionais e até pessoais. Foram gerados mapas cartográficos e gráficos que representam tais questões e respostas obtidas durante a coleta de dados.

Percebe-se que a maioria das 44 respostas coletadas é de docentes com idade entre 31 e 40 anos, ou seja, no auge das suas carreiras acadêmicas e profissionais, conforme GRÁFICO 02 abaixo:

GRÁfICO 2 - Faixa etária dos docentes do CAV

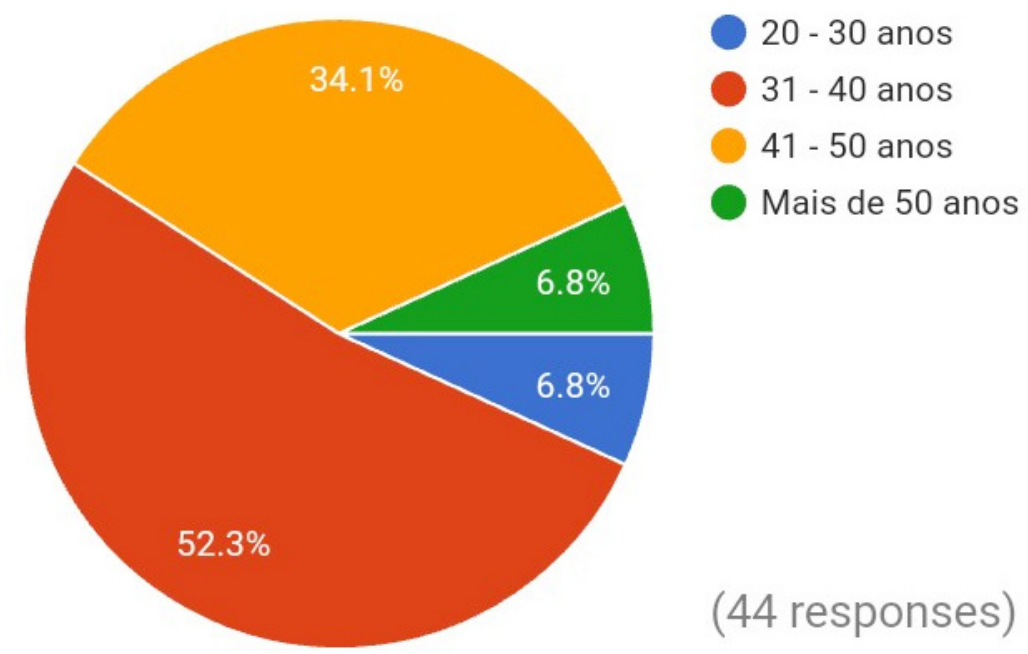

FONTE: Elaborado pela autora, 2017. 
Quando perguntando sobre o que fez o docente vir trabalhar no CAV/UFPE, podemos observar que no GRÁfICO 3 abaixo 54,5\% respondeu que estava em busca de novas oportunidades, $34,1 \%$ buscava mais chances de se desenvolver profissionalmente e apenas $11,4 \%$ respondeu que buscava qualidade de vida, ou seja, a maioria estava visando novas oportunidades de trabalho, provavelmente pelo fato do CAV ser um Campus novo, em crescimento.

GRÁFICO 03 - Motivos que levaram à escolha do cAv como local de trabalho.

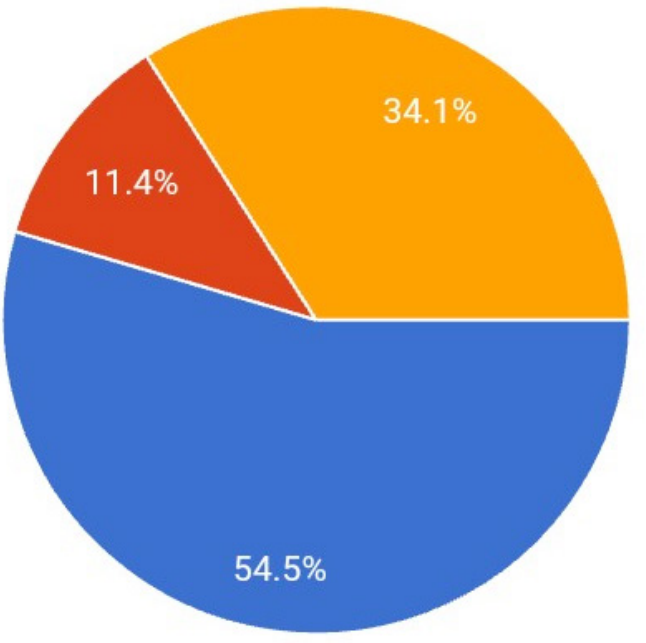

FONTE: Elaborado pela autora, 2017.
Novas oportunidades

Qualidade de vida

Mais chances de se desenvolver profissionalmente

\section{4 respostas}

No GRÁfICO 4 abaixo podemos confirmar que os docentes alcançaram suas metas respondidas no gráfico anterior $(88,6 \%$ alcançaram sua meta pretendida), confirmando assim a teoria que um Campus do interior pode trazer novas oportunidades de trabalho e de desenvolvimento na vida profissional como também qualidade de vida aos que buscam.

GRÁFICO 4 - Alcançou a sua meta respondida na questão anterior ou está perto de alcançar?

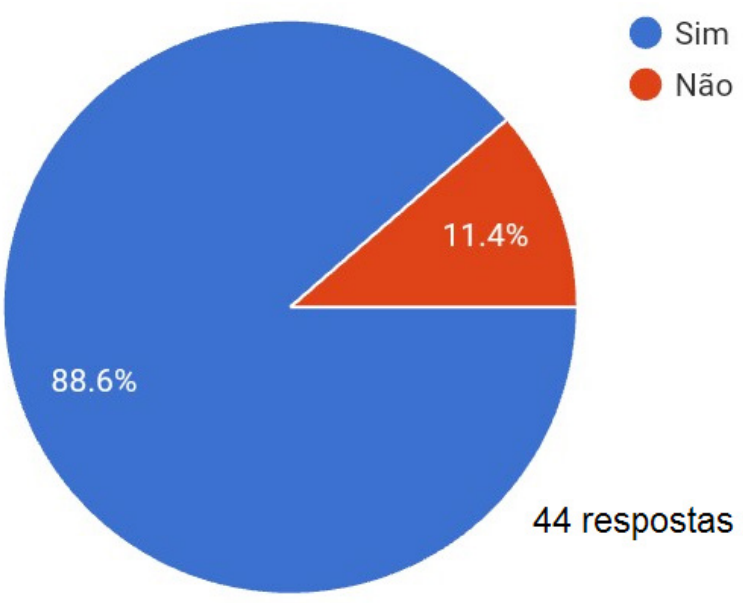

FONTE: Elaborado pela autora, 2017. 
No GRÁfICO 5 verifica-se que 52,3\% está no CAv há mais de 6 anos, ou seja, participaram efetivamente na implantação e desenvolvimento dos primeiros 5 anos do Campus, sendo extremamente importantes para o processo de interiorização do mesmo. Em relação a isso, a maioria dos docentes que participaram da implantação do CAV também tem a intenção em permanecer no Centro pelo menos nos próximos 5 anos, conforme GRÁfICO 6 abaixo que mostra que 88,6\% afirmou que tem essa intenção.

GRÁFICO 05 - Há quantos anos ingressou no CAV/UfPE?

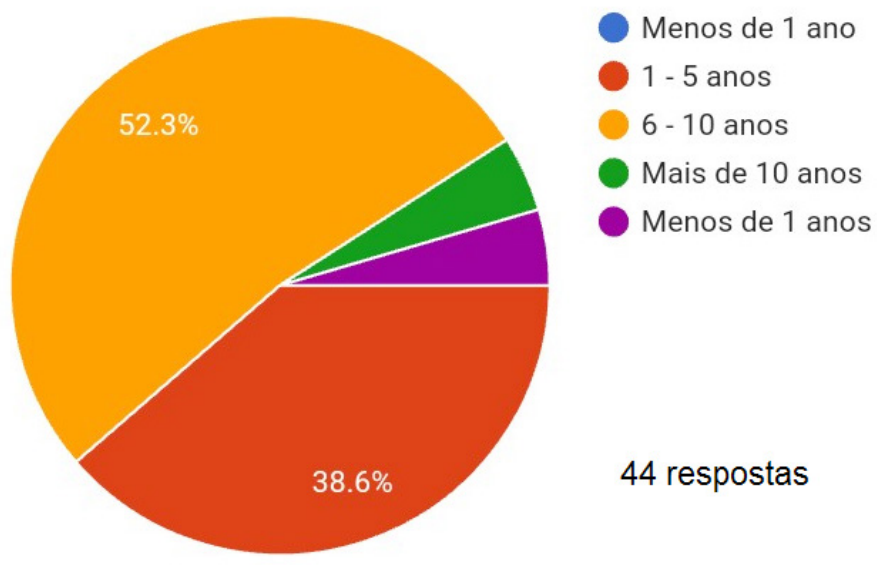

FONTE: Elaborado pela autora, 2017.

GRÁFICO 06 - Pretende ficar no CAV nos próximos 05 anos?

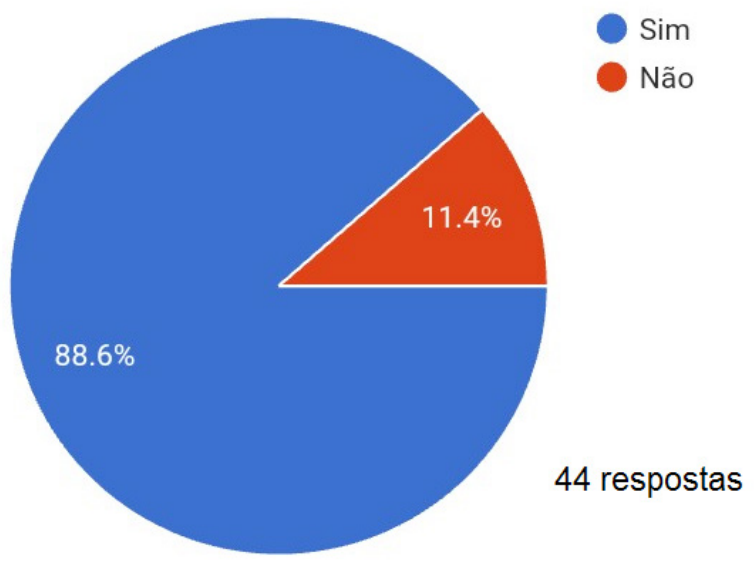

FONTE: Elaborado pela autora, 2017.

Com relação ao GRÁFICO 7, a seguir, podemos observar que a maioria dos docentes que responderam ao questionário, 88,6\% informaram que desenvolvem ou já desenvolveram projetos na cidade de Vitória de Santo Antão, colaborando assim com a qualidade de vida da população e mais conhecimento, como também com questões acadêmicas relacionadas aos seus projetos, trazendo grande contribuição para a cidade e seus habitantes. 
GRÁFICO 07 - Desenvolve ou já desenvolveu projetos do CAv/UFPe na cidade de Vitória de Santo Antão?

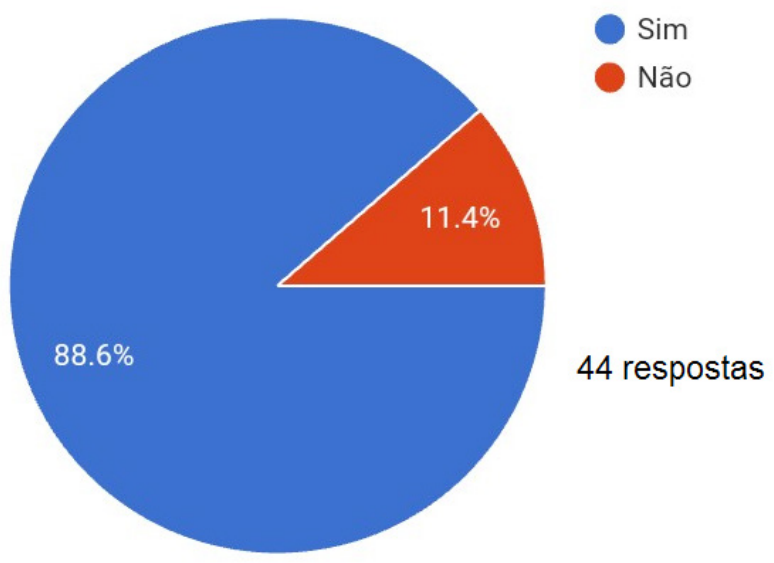

FONTE: Elaborado pela autora, 2017.

No MAPA 1 são apresentados os dados que dizem respeito a cidade de origem dos docentes do CAV, onde foi observado que a maioria pesquisada vem da região nordeste, sudeste e sul e inclusive um docente oriundo da Argentina, distribuído em 19 cidades diferentes localizadas em 8 estados brasileiros e 1 na Argentina.

Verificou-se que $36,4 \%$ são oriundos da cidade de Recife/PE, 6,8\% de João Pessoa/Pв, 6,8\% do Rio de Janeiro/RJ, seguidos de São Paulo/sP, Porto Alegre/Rs e Olinda/PE (todos com 4,5\% cada), sendo o restante distribuídos nos Estados da Bahia, Ceará, Distrito Federal e na Argentina. Com relação ao estado de origem, Pernambuco aparece com 52,3\%, seguido da Paraíba com 9,1\%. Concluindo, portanto, que os docentes residentes na capital pernambucana e em outras capitais desenvolvidas em vários aspectos buscaram uma cidade do interior para trabalharem e possivelmente perceberam que isso poderia favorecê-los de alguma maneira em suas vidas pessoal, acadêmica e profissional.

MAPA 1 - Mapeamento de Cidade de Origem dos Docentes do cav/ufpe

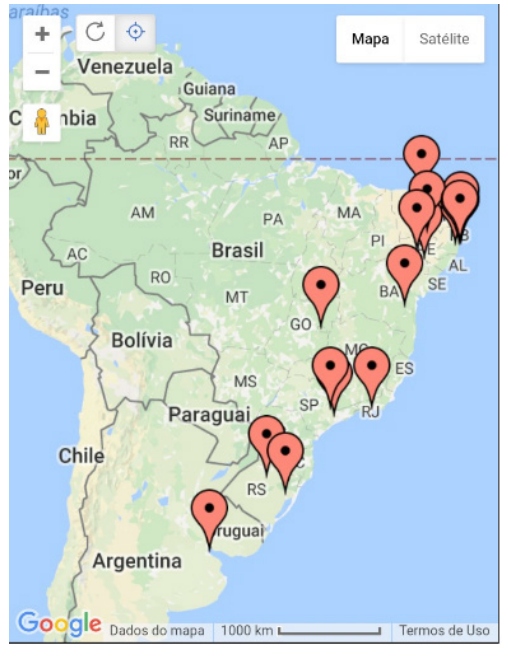

FONTE: BatchGeo - 2017, elaborado pela autora. 
No GRÁfICO 08 e MAPA 02 abaixo se pode observar que os docentes pesquisados residem em sua maioria na cidade de Recife/ PE $(63,3 \%)$, seguida de Gravatá/PE (13,6\%) e 9,1\% em Vitória de Santo Antão/PE, ou seja, $22,7 \%$ resolveram viver e trabalhar em uma cidade do interior, buscando qualidade de vida para si e sua família, como também uma questão de uma melhor logística por morar próximo ao seu local de trabalho.

GRÁFICO 08 - Cidade que reside

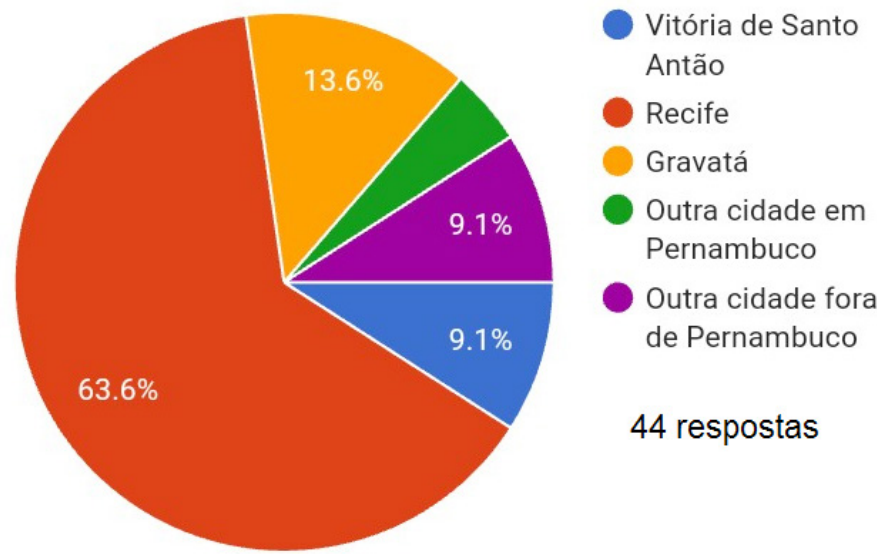

FONTE: Elaborado pela autora, 2017

MAPA 02 - Mapeamento do local de Residência dos Docentes do cAv/UfPE

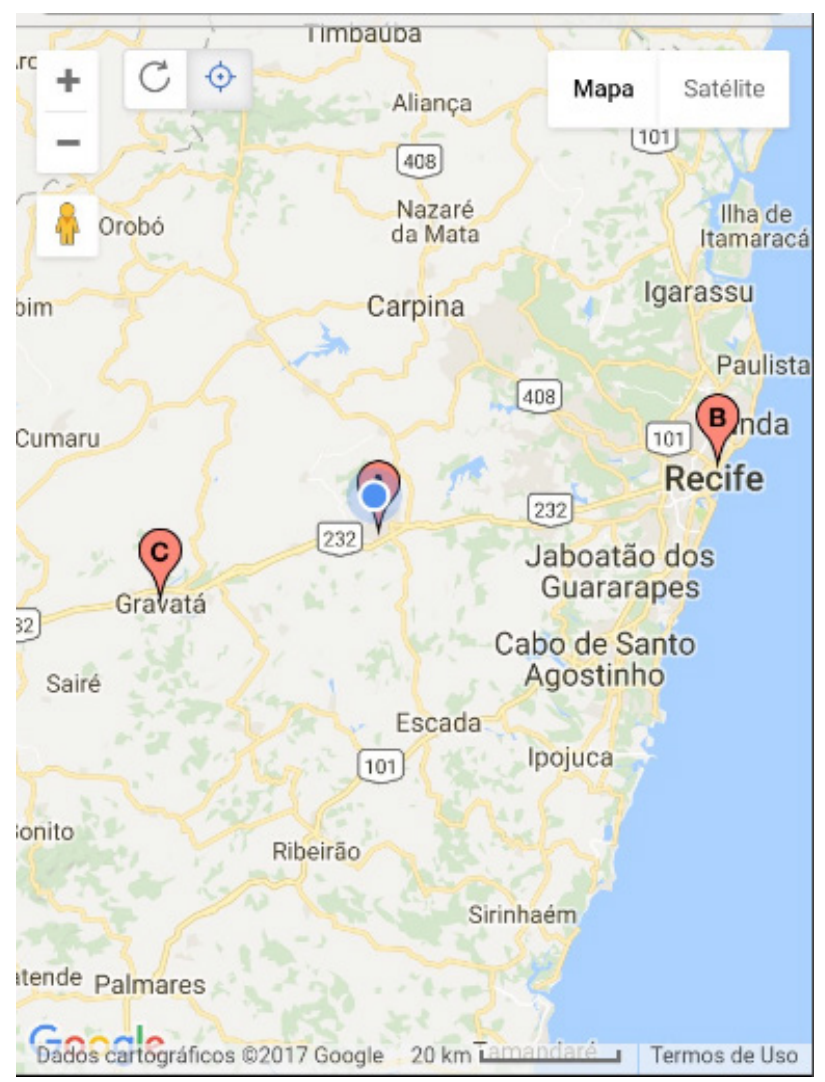

FONTE: BatchGeo - 2017, elaborado pela autora. 


\section{CONCLUSÕES}

Este trabalho procurou fazer uma análise sobre a cidade de origem dos docentes do Centro Acadêmico de Vitória/ufpe e a percepção dos mesmos com relação a essa mudança em suas vidas, como também os possíveis efeitos causados no processo de implantação e desenvolvimento do CAV nos últimos 10 anos e até mesmo a sua influência na cidade de Vitória de Santo Antão, através de desenvolvimento de projetos, eventos, etc, local onde está implantado o referido Campus.

Diante dos dados coletados e analisados, percebe-se que a maioria dos docentes que saíram de suas cidades natal para investirem suas vidas em uma cidade do interior, muitas vezes fora dos seus estados de origem, tiveram um retorno satisfatório e positivo após essa mudança, onde grande parte dos pesquisados conseguirem atingir suas metas, como também apresentarem interesse em continuar no cAV desenvolvendo suas pesquisas, trabalhos acadêmicos, projetos de vida pessoal e profissional, colaborando assim com o crescimento do cAV e da cidade de Vitória de Santo Antão.

Essa migração dos docentes para uma cidade do interior apresentou estreita relação entre a busca por novas oportunidades, qualidade de vida e mais chances de se desenvolverem academicamente e profissionalmente e que isso provoca mudanças importantes, principalmente no desenvolvimento acadêmico da população jovem, como também com relação a projetos que passam a ser desenvolvidos dentro da própria cidade, melhorando assim a qualidade de vida da população e dos envolvidos na comunidade acadêmica e por se tratar de uma universidade federal reconhecida internacionalmente, pode também atrair estudantes de outros lugares do país e também de fora do país.

Após essa pesquisa, foi percebida uma necessidade de estudos mais aprofundados sobre essa realidade dos Campi implantados no interior das capitais e as várias formas da Universidade em interagir com a sociedade e a comunidade local. Como também as oportunidades surgidas a partir da implantação de um Centro Acadêmico aos vários tipos de profissionais, como técnicos administrativos e docentes diretamente ligados à Universidade, como também aos alunos que conseguem uma chance a mais de se graduarem e se profissionalizarem em suas respectivas áreas de interesse, sem ter a necessidade de saírem de suas cidades para isso.

\section{REFERÊNCIAS}

ACERVO DO CONHECIMENTO - ACH. Mapas Antigos do

Brasil. Disponível em: < http://achistorico.blogspot.com.br/2016/o9/ mapas-antigos-do-brasil.html >. Acesso em 15 abr. 2017.

ARAÚJO, T. B. Desenvolvimento regional brasileiro e políticas públicas federais no Governo Lula in SADER. E (org). 1o Anos de governos pós-neoliberais no Brasil. Rio de Janeiro: Boitempo, 2013. 
BARCELAR, J. Guia Geográfico, mapas históricos. História da Cartografia. 2015. Disponível em: <http://www.mapas-historicos. com/cartografia-historia.htm>. Acesso em: 09 abr. 2017.

BATCHGEO. Criação de Mapas. Disponível em: <https:// pt.batchgeo.com/> Acesso em 07 abr. 2017.

BLOG - JÁ ANDEI POR AÍ. Mapa do Turismo Brasileiro passará por nova atualização. Disponível em: $<\mathrm{http}: / /$ jaandeiporai.com.br/mapa-do-turismo-brasileiro-passarapor-nova-atualizacao/>. Acesso em 15 abr. 2017.

CHAUÍ, Marilena. A universidade pública sob nova perspectiva. Disponível em: <http://www.scielo.br/pdf/ rbedu/n24/n24ao2.pdf >. Acesso em: 29 jul. 2013.

ETZKOWITZ, Henry. Hélice Tríplice - universidade-indústriagoverno: Inovação em Movimento. Porto Alegre: EdiPUCRS, 2009.

FRANCISCO, Wagner de Cerqueria e. "Migração interna no Brasil"; Brasil Escola. Disponível em <http://brasilescola.uol.com.br/ brasil/migracao-interna-no-brasil.htm $>$. Acesso em 10 de abril de 2017.

FREIRE, N. C. F.; FERNANDES, A. C. de A. Mapas como expressão de poder e legitimação sobre o território: uma breve evolução histórica da cartografia como objeto de interesse de distintos grupos sociais. III Simpósio Brasileiro de Ciências Geodésicas e Tecnologias da Geoinformação. Recife, 2010. Disponível em: $<$ https://www.ufpe.br/cgtg/SIMGEOIII/IIISIMGEO_CD/artigos/ CartografiaeSIG/Cartografia/A_244.pdf >. Acesso em: 15 abr. 2017.

GOOGLE DOCS. Criação de Formulários Eletrônicos. Disponível em: <https://www.google.com/docs/> Acesso em 02 abril 2017.

IBGE, IBGE. Noções Básicas de Cartografia. Disponível em:<https:// www.ibge.gov.br/home/geociencias/cartografia/manual_nocoes/ processo_cartografico.html . Acesso em: 11 abr. 2017.

MARTINELLI, Marcelo. Mapas da geografia e cartografia temática. São Paulo: Editora Contexto, 2003.

MEC - Ministério da Educação. PE tem mais vagas no ensino superior. Disponível em: $<$ http://portal. mec.gov.br/>. Acesso em: 15 abr. 2017.

MCCOWAN, T. Expansion without equity: An analysis of current policy on access to higher education in Brazil. Higher Education, v. 53, n.5, p. 579-598. 2007.

$\mathrm{MOÇO}$, Anderson. A história dos mapas e sua função social. Disponível em: <https://novaescola.org.br/conteudo/347/ahistoria-dos-mapas-e-sua-funcao-social>. Acesso em: 15 abr. 2017. 
SANTANA, Rogério. Êxodo e Democracia. Inversão do Êxodo Rural. Disponível em <http://exodoedemocracia.blogspot.com. br/2013/o5/inversao-do-exodo-rural.html >. Acesso em 10 abr. 2017.

UFPE. ASCOM. Interiorização da UFPE. 2013. Disponível em: $<$ http://www.ufpe.br/agencia/index.php?option=com_ content\&view $=$ article\&id=47148interiorizacao-da-ufpe\&catid $=19 \&$ Itemid $=72>$. Acesso em: 13 abr. 2017 .

CAA. Centro Acadêmico do Agreste. 2013. Disponível em: <http://www.ufpe.br/caa/>. Acesso em: 12 abr. 2017.

CAV. Centro Acadêmico de Vitória. 2013. Disponível em: <www.ufpe.br/cav/>. Acesso em: 11 abr. 2017.

Centro Acadêmico de Vitória. Relatório CAV 2009. Vitória de Santo Antão: CAV/

UFPE, 2010. Disponível em: <https://www.ufpe.br/ cav/images/Docs_Publicacoes/Arquivos_Gerais/ relatorio_cav_2009.pdf $>$. Acesso em: 08 abr. 2017.

Centro Acadêmico de Vitória. Relatório CAV 2008. Vitória de Santo Antão: CAV/

UFPE, 2009. Disponível em: <https://www.ufpe.br/ cav/images/Docs_Publicacoes/Arquivos_Gerais/ relatorio_cav_2008.pdf $>$. Acesso em: 7 abr. 2017.

Sistema de Gerenciamento Acadêmico UFPE. SIG@ Versão 3.14.3.6. Todos os Direitos Reservados à UFPE-NTI.

TEIXEIRA, P. N; ROCHA, V; BISCAIA, R; CARDOSO, M. F. Competition and diversity in higher education: an empirical approach to specialization patterns of Portuguese institutions. Higher Education, v.63, n.3, p.337-352 Mar. 2012.

WIKIPÉDIA - A Enciclopédia Livre. Migração

interna no Brasil. Disponível em: < https:// pt.wikipedia.org/wiki/Migra\% $\% \mathrm{C}_{3} \% \mathrm{~A}_{7} \% \mathrm{C}_{3} \% \mathrm{~A}_{3} \mathrm{O}_{-}$ interna_no_Brasil>. Acesso em: 15 abr. 2017. 